\title{
Diet assessment in the Brazilian Longitudinal Study of Adult Health (ELSA-Brasil): Development of a food frequency questionnaire
}

\author{
Avaliação da dieta no Estudo Longitudinal \\ de Saúde do Adulto (ELSA-Brasil): \\ desenvolvimento do Questionário \\ de Frequência Alimentar
}

Maria del Carmen Bisi MOLINA'

Carolina Perim de FARIA ${ }^{1}$

Letícia de Oliveira CARDOSO²

Michele DREHMER ${ }^{3}$

Jorge Gustavo VELASQUEZ-MELÉNDEZ ${ }^{4}$

Andrea Lizabeth Costa GOMES 5

Cristiane MELERE ${ }^{3}$

Maria de Fátima Haueisen Sander DINIZ ${ }^{6}$

Rosely SICHIERI ${ }^{7}$

Isabela Judith Martins BENSEÑOR ${ }^{8}$

\section{A B S T R A C T}

\section{Objective}

The objective of this article is to present the development of the Food Frequency Questionaire used in the Longitudinal Study of Adult Health-Brazil and analyze how diet exposes individuals to cardiovascular diseases and type 2 diabetes Mellitus.

\footnotetext{
1 Universidade Federal do Espírito Santo, Centro de Ciências da Saúde, Departamento de Educação Integrada em Saúde. Av Marechal Campos, 1468, Maruípe, 29042-751, Vitória, ES, Brasil. Correspondence to/Correspondência para: MCB MOLINA. E-mail: <mdmolina@uol.com.br>.

2 Fundação Oswaldo Cruz, Departamento de Epidemiologia. Rio de Janeiro, RJ, Brasil.

3 Universidade Federal do Rio Grande do Sul, Faculdade de Medicina, Programa de Pós-Graduação em Epidemiologia. Porto Alegre, RS, Brasil.

${ }^{4}$ Universidade Federal de Minas Gerais, Escola de Enfermagem, Departamento de Enfermagem Materno Infantil e Saúde Pública. Belo Horizonte, MG, Brasil.

${ }^{5}$ Universidade Federal da Bahia, Escola de Nutrição, Departamento da Ciência da Nutrição. Salvador, BA, Brasil.

${ }^{6}$ Universidade Federal de Minas Gerais, Faculdade de Medicina, Departamento de Clinica Médica. Belo Horizonte, MG, Brasil.

7 Universidade Estadual do Rio de Janeiro, Instituto de Medicina Social, Departamento de Epidemiologia. Rio de Janeiro, RJ, Brasil.

${ }^{8}$ Universidade de São Paulo, Faculdade de Medicina, Departamento de Ciências Médicas. São Paulo, SP, Brasil.
} 
168 | MCB MOLINA et al.

\section{Methods}

The Longitudinal Study of Adult Health-Brazil dietary assessment instrument is based on a previously validated Food Frequency Questionaire and the final list of items took into consideration a study done in the six Longitudinal Study of Adult Health-Brazil investigation centers.

\section{Results}

New foods/preparations were included in the Food Frequency Questionaire with their respective portions, totaling 114 items. The perspectives of dietary analysis and cardiovascular diseases and diabetes are presented in Longitudinal Study of Adult Health-Brazil.

\section{Conclusion}

A new instrument was developed to cover the regional particularities of the study population.

Indexing terms: Chronic disease. Food consumption. Nutrition surveys.

\section{R E S U M O}

\section{Objetivo}

Este artigo tem por objetivo apresentar o desenvolvimento do Questionário de Frequência Alimentar utilizado no Estudo Longitudinal de Saúde do Adulto e as perspectivas de análise da dieta, como exposição a doenças cardiovasculares e diabetes Mellitus tipo 2.

\section{Métodos}

O instrumento de avaliação dietética do Estudo Longitudinal de Saúde do Adulto foi construído a partir de um Questionário de Frequência Alimentar previamente validado. A lista final de itens alimentares levou em consideração um levantamento realizado nos seis centros de investigação do estudo em questão.

\section{Resultados}

Foram incluídos novos alimentos/preparações no Questionário de Frequência Alimentar, com as respectivas porções, perfazendo um total de 114 itens. São apresentadas as perspectivas de análise da dieta e doenças cardiovasculares e diabetes no Estudo Longitudinal de Saúde do Adulto.

\section{Conclusão}

Desenvolveu-se um novo instrumento que busca atender especificidades regionais contempladas na população do estudo.

Termos de indexação: Doença crônica. Consumo de alimentos. Inquéritos nutricionais.

\section{INTRODUCTION}

Dietary aspects have been associated with cardiovascular diseases ${ }^{1}$ and type 2 diabetes Mellitus ${ }^{2}$. The role of diet as main risk factor, confounding variable, or effect modifier between other factors and these diseases has been analyzed by the main cohort studies in the world. These analyses are based on the results of studies that used dietary questionnaires, especially Food Frequency Questionnaires (FFQ) based on that developed by Willett et al. ${ }^{3}$ and Block et al. ${ }^{4}$.

The Nurses Health Study (http://www. channing.harvard.edu/nhs/), which began in 1976 and enrolled 238,000 American nurses, initially aimed to study the use of oral contraceptives and cancer ${ }^{5}$. After four years, a dietary questionnaire was included in the study. Among the results, more than 300 publications reported associations between diet and different outcomes. A recent study of this cohort showed that adherence to a Mediterranean dietary pattern is a protective factor against Cardiovascular Disease (CVD) incidence and mortality ${ }^{6}$. The following associations were observed: between fat intake and decline of cognitive function in diabetic women ${ }^{7}$; between adherence to the Dietary Approaches to Stop Hypertension (DASH) diet and 
lower incidence of self-reported hypertension in young women ${ }^{8}$; and between the intake of long-chain fatty acids and fish and lower incidence of type 2 diabetes Mellitus ${ }^{9}$. Fruit and vegetable intake is associated with a lower occurrence of ischemic cardiovascular diseases in women with moderate carbohydrate intake ${ }^{10}$.

The findings of the Framingham study were relevant for the current knowledge on CVD prevention and contribute significantly to clinical practice (http://www. framinghamheartstudy.org) ${ }^{11}$. Meanwhile, the Whitehall study (http://www. ucl.ac.uk/whitehallII) has valued the longitudinal analysis of dietary patterns found by FFQ and their association with the incidence of CVD and type 2 diabetes Mellitus ${ }^{12,13}$.

Multicausality, the difficulty of determining the diet and the countless potentialy interactions with sociodemographic and lifestyle factors make the association between diet and the incidence of CVD and type 2 diabetes Mellitus complex, but the importance of this analysis is illustrated by the systematic review of 11 studies that use FFQ to verify the association between intake of fatty acids and carbohydrates and risk of CVD. In the cited review, replacing $5 \%$ of the total energy from saturated fatty acids with polyunsaturated fatty acids was inversely associated with risk of ischemic heart disease. However, replacing the same $5 \%$ of the total energy from saturated fatty acids with carbohydrates showed a modest but positive association with ischemic heart disease ${ }^{1}$.

The Longitudinal Study of Adult Health (Estudo Longitudinal de Saúde do Adulto ELSA-Brasil) is a cohort, multicentric and interdisciplinary study that aims to assess the complex network of risk factors associated with CVD and type 2 diabetes Mellitus, including diet. The ELSA cohort consists of 15,105 participants aged 35 to 74 years, employees and retirees of the following six teaching and research institutions: Universidade Federal da Bahia, Universidade Federal do Espírito Santo, Universidade Federal de Minas Gerais, Universidade de São Paulo,
Fundação Oswaldo Cruz and Universidade Federal do Rio Grande do Sul.

The ELSA-Brasil is a prospective cohort structured on an emerging country with great dietary diversity which is undergoing changes that may have promoted obesity, among other determinants of chronic diseases, and Brazilian dietary practices ${ }^{14}$. The option of using a FFQ in ELSA-Brasil is based on the supposition that the mean dietary intake during a relatively long period, for example, the previous year (used in ELSA-Brasil) is a more representative exposure that the dietary intake of a few days ${ }^{3}$. Even if limited by exposure time, individuals seem to maintain a consistent intake pattern during adulthood, so the intake during the last year probably reflects the dietary pattern of a longer period.

Although important and necessary, a consensus could not be reached on the dietary assessment method to be used by ELSA-Brasil. After discussing how to make this assessment, if by a FFQ, a method commonly used in longitudinal studies, or by many 24 hour food recalls, the FFQ method was chosen. Although the limitations of their use are known, FFQ have many advantages over other assessment methods, such as: simple to analyze, inexpensive, does not induce changes in food intake since it collects food intake data over time, minimizes intra-individual variation, provides food data directly and can improve the analysis of nutrients with high intra-individual variation ${ }^{15}$.

The objective of this article is to present the development of the FFQ used in the first phase of ELSA-Brasil and the perspectives of dietary analysis, such as cohort exposure to CVD and type 2 diabetes Mellitus.

\section{Food frequency questionnaire ELSA-Brasil}

Longitudinal Study of Adult Health-Brazil used a semi-quantitative FFQ with 114 items for assessing the food intake of the participants in 
the last twelve months. A sample question is: "How often do you eat rice? Please refer to your habitual intake in the last 12 months".

The Food Frequency Questionnaire ELSA-Brasil was based on a FFQ developed in Brazil during the 1990s with a list of foods extracted from 1974-1975 population surveys, including items that represented $86 \%$ of the energy, $84 \%$ of the vitamin $A$ and $76 \%$ of the vitamin $C$ consumed at the time ${ }^{16}$. It performed similarly to instruments used in other large studies $^{17}$. In addition to the original food items, new food items were included in the FFQ ELSA-Brasil to reflect the dietary changes that have occurred in the last 20 years.

Chart 1 shows the FFQ ELSA-Brasil template. It consists of three components: 1.
Foods/preparations; 2. Portion sizes; and 3. Intake frequencies, with 8 frequency options varying from "More than 3x daily" to "Never/Almost never". In order to include seasonal consumption, one more column was included where it is possible to record the occurrence of spontaneous manifestation, such as "only during a certain period", "only during the season", or any other expression that indicates regular consumption during a certain time of the year.

\section{List of foods and/or preparations}

The original FFQ was developed in Rio de Janeiro and did not include regional foods. Consequently, a previous study used 24 hour recalls in the six ELSA study centers. A total of

Chart 1. Template of the Food Frequency Questionnaire of the Longitudinal Study of Adult Health (ELSA-Brasil) 2008.

DIETA (QFA)

"Now let's talk about your habitaul food intake during the last 12 months. We would like to know what you eat and drink daily, weekly or monthly, as shown in this card. [Present the card DIE 01] I will read food by food. Tell me which ones you consume and how much of each. These utensils will be used to help to quantify the foods and beverages. [Present the utensils.] May we begin?

"I am going to start by listing the foods in the Group breads, grains and tubers.Pleaser report your habitual intake during the last 12 months".

"How often do you eat or drink [say the name of the food]?" If the interviewee does not specify a frequency, ask: "How many times a day, week or month?" "And how many [say the corresponding cooking unit showing the utensil] do you eat or drink?" Repeat these instructions for all foods.

\begin{tabular}{|c|c|c|c|c|c|c|c|c|c|c|c|}
\hline & Food & $\begin{array}{l}\text { Amount eaten } \\
\text { each time }\end{array}$ & $\begin{array}{c}\text { More } \\
\text { than } \\
3 x / \text { day }\end{array}$ & $\begin{array}{l}2 \text { to } \\
3 x / \\
\text { day }\end{array}$ & $1 x /$ day & $\begin{array}{c}5 \text { to } \\
6 \mathrm{x} / \\
\text { week }\end{array}$ & $\begin{array}{c}2 \text { to } \\
4 \mathrm{x} / \\
\text { week }\end{array}$ & $\begin{array}{c}1 \mathrm{X} / \\
\text { week }\end{array}$ & $\begin{array}{c}1 \text { to } \\
3 x / \\
\text { week }\end{array}$ & $\begin{array}{l}\text { Rarely/ } \\
\text { Never }\end{array}$ & $\begin{array}{c}\text { Reported } \\
\text { seasonal } \\
\text { intake }\end{array}$ \\
\hline 1 & $\begin{array}{ll}\text { Rice } & (\text { ) Whole } \\
& (\text { ) White }\end{array}$ & Serving Spoon & & & & & & & & & \\
\hline 2 & Oats/Granola/Bran/Other Grains & $\begin{array}{c}- \\
\text { Serving Spoon }\end{array}$ & & & & & & & & & \\
\hline 3 & $\begin{array}{l}\text { Farofa/Savory couscous/Paulista } \\
\text { couscous }\end{array}$ & Full Tablespoon & & & & & & & & & \\
\hline 4 & Manioc (Casava) Flour/Commeal & $\begin{array}{c}- \\
\text { Full Tablespoon }\end{array}$ & & & & & & & & & \\
\hline 5 & Light Bread (White or whole) & $\begin{array}{c}- \\
\text { Slice }(25 g)\end{array}$ & & & & & & & & & \\
\hline
\end{tabular}

Note: *Study done in the following six teaching and research institutions: Universidade Federal da Bahia, Universidade Federal do Espírito Santo, Universidade Federal de Minas Gerais, Fundação Osvaldo Cruz, Universidade Federal do Rio Grande do Sul and Universidade de São Paulo. 
10024 hour recalls were administered to individuals ineligible for the study, but with characteristics similar to those of the ELSA study participants (same age group, gender and work location). Trained interviewers administered 5024 hour recalls to individuals with higher education and 50 to individuals with elementary school education. Among the correctly assessed 24 hour recalls, half regarded one weekday (Monday to Friday) and the other half one weekend day (Saturday or Sunday). In order to standardize the administration of the 24 hour recalls, a specific protocol with an instruction manual was developed and a picture album with food portions and utensils was used together with the recalls. After the analysis, the frequencies of the items recorded in the forms were determined.

In addition to the foods in the original version ${ }^{16}$, the preliminary list of foods in the FFQ ELSA-Brasil contained food/preparations and beverages recorded in these 24 hour recalls (for example, rice, beans) with consumption frequencies greater than $10 \%$. Later, the inclusion of typical or common foods in each state of the study was considered, and the researchers decided to include up to two regional items or markers of differentiated consumption, such as: food typical from Bahia and acarajé (BA), chimarrão and cuca (RS), Paulista couscous and Japanese food (SP); feijoada (RJ); cheese bun and tropeiro beans (MG) and Capixaba seafood stew and fried plantains (ES). Regional synonyms and designations for different foods were also included, such as pão francês and cacetinho for French bread roll, tangerina and bergamota for mandarin, doce de fruta and chimia for a type of jam, mandioca and aipim for cassava, and polenta and angu for polenta.

Increasing the number of items from the original questionnaire increases the probability of overestimating intake $\mathrm{e}^{3}$ and the time needed for administration. In order to adjust the size of the FFQ administered at the ELSA Investigation Centers (IC) to what seemed a reasonable size and minimize participant tiredness, some items were grouped as shown in Chart 2. The grouping of items obeyed the rule of similar nutritional content, that is, foods were grouped with other foods with similar nutritional composition, and the intake characterization rule, that is, foods consumed in similar situations and commonly used for replacing each other were also grouped.

Eleven items added to the FFQ also received options for type: rice could be white or whole, cookie could be plain or sandwich, fruit salad could be with sugar or dressing or without sugar or dressing, mayonnaise could be regular or light, milk could be whole, skimmed, semiskimmed or soy milk, yogurt could be regular or light, cream cheese (requeijão) could be regular or light, food from Bahia could be vatapá, caruru or fish stew, Japanese food could be sushi, sashimi, tofu or yakisoba, soda could be diet, light or regular and wine could be red or white.

In order to improve the assessment of sweetened beverages without increasing the number of items, the option "without sugar/with sugar/with sweetener" was added for five beverages: coffee, natural juice, processed juice, and tea/mate. The participant would choose the version consumed most often in the last 12 months.

Finally, all items selected for the FFQ ELSA-Brasil were organized into the following seven food groups for FFQ administration: breads/ grains/tubers; fruits; vegetables/legumes; eggs/ meats/milks/dairy products; pasta/other preparations; sweets; and beverages. Hence, the version used in the first phase of the ELSA-Brasil was concluded with a list of 114 food items.

\section{Portion sizes}

Some cooking units of the original FFQ ${ }^{16}$ were changed after administration of the 24 hour recalls. For each item, the cooking unit used most often was used. The amount in grams (g) or milliliters $(\mathrm{mL})$ for each cooking unit was taken 
172 | MCB MOLINA et al.

Chart 2. List of food groups of the Food Frequency Questionnaire of the Longitudinal Study of Adult Health (ELSA-Brasil), 2009.

\begin{tabular}{|c|c|}
\hline Group & Grouped foods \\
\hline Breads, Grains and Tubers & $\begin{array}{l}\text { Oat/Granola/Bran/Other grains. } \\
\text { Farofa/Savory couscous/Paulista couscous. } \\
\text { Cassava flour/cornmeal. } \\
\text { French bread roll/Bread loaf/Syrian bread/toast. } \\
\text { Sweet bread/Homemade bread. } \\
\text { Stuffed cake/pie/trifle/cuca. } \\
\text { Polenta/angu/pirão. } \\
\text { Cooked potato/potato stew/mashed potato. } \\
\text { Potato/cassava/banana/polenta/sweet potato/French fries. }\end{array}$ \\
\hline Fruits & $\begin{array}{l}\text { Orange/mandarin/tangerine/Ponkan. } \\
\text { Apple/pear. } \\
\text { Peach/plum/kiwi/cashew apple/Spondias mombin/nectarine. } \\
\text { Persimmon/jack fruit/pine nuts/custard-apple. }\end{array}$ \\
\hline Vegetables and legumes & $\begin{array}{l}\text { Steamed cabbage/spinach. } \\
\text { Chicory/watercress/arugula/cabbage/endive/chard/raw spinach. } \\
\text { Zucchini/chayote/eggplant. } \\
\text { Lentils/Chickpeas/Peas. }\end{array}$ \\
\hline Eggs, meats, milks and dairy products & $\begin{array}{l}\text { Fried egg/omelet/scrambled eggs. } \\
\text { Frescal Minas cheese/ricotta/cottage/buffalo mozzarella. } \\
\text { Standard Minas cheese/mozzarella/Prato/cheddar/canastra/Processed. } \\
\text { Liver/organ meats. } \\
\text { Chicken breast/genetically improved chicken/turkey. } \\
\text { Sausage/spicy sausage. } \\
\text { Blanquette/turkey breast/breast from genetically improved chicken. } \\
\text { Ham/mortadella/capico/a/salami/pâté. } \\
\text { Bacon/lard/crackling. } \\
\text { Cooked fish/Capixaba seafood stew/baked fish/fish stew/grilled fish. } \\
\text { Sardine/tunaShrimp/mussel. }\end{array}$ \\
\hline Pasta and other preparations & Feijoada/tropeiro beans. \\
\hline Sweets and beverages & Cocoa powder/chocolate milk/Capuccino. \\
\hline
\end{tabular}

from a standard reference table proposed by Pinheiro et al. ${ }^{18}$. When the cooking unit most often cited in the 24-hour recalls was not found in the table, it was measured in the laboratory by a precision scale and appropriate methodology. This same procedure was used for developing cooking unit equivalents when the interviewee was unable to report intake in cooking units.

A checklist was created for some food groups and placed in the general ELSA-Brasil questionnaire right after the FFQ. These are food habit-related questions, such as "How often do you eat fast food (pizza, sfiha, kibbeh, coxinha, hamburger, acarajé?;" six with the same frequency options as the FFQ and eleven with specific answers, such as: "What type of sweet do you consume most often?" and "What kind of cooking oil do you use at home to cook/prepare foods?"

The present study was approved by the National Research Ethics Committee under protocol number 15065 Comissão Nacional de Ética em Pesquisa (CONEP) and by all Research Ethics Committees of the participant institutions. All participants signed a free and Informed Consent form before entering the study.

\section{Administration of the FFQ ELSA-Brasil}

ELSA-Brasil is the first Brazilian study to use a FFQ filled out online during the participants' interviews. The construction of the online version 
allowed controlling input by establishing minimum and maximum acceptable limits for each one of the 114 items and avoiding errors while filling out the instrument, such as skipping questions and leaving blank answers. The probable equivalency of each food item or beverage could be shown while asking about it, helping the interviewer to select the appropriate cooking unit.

A list of foods was read to the participants and they were asked which ones they consumed habitually in the last twelve months and how many times a day/week/month they consumed them. An answer card size A4 was provided to facilitate selection and keep the participants from having to memorize the options. Additionally, a kit of utensils was used during FFQ administration. The answer card shown to the participant had the frequencies grouped as daily, weekly or monthly consumption. Utensils that represented a standardized portion in the FFQ were shown to the participants during the interviews to help of estimation the amount of food, preparations and beverages consumed.

The interviewers were trained and certified by ELSA researchers. Also, during the study, interviews were periodically followed by an IC supervisor, according to the instruction manual. After introduction to the FFQ and training, the interviewers were theoretically and practically assessed before being considered apt and certified for FFQ administration. The interviews were periodically taped for quality control and some interviews were randomly chosen for assessment of interviewer performance by the local supervisors.

\section{Analysis of the dietary data}

The Food Frequency Questionnaire ELSA-Brasil uses the Nutrition Data System for Research (NDSR) table and Tabela Brasileira de Composição de Alimentos (TACO) (http://www. unicamp.br/nepa/taco/) for calculating the dietary nutrients. The NDSR database contains more than
18,000 foods and 7,000 processed products. The database also allows the user to pick ingredients and preparation methods for better results. The nutritional composition of the 114 items listed in the FFQ ELSA-Brasil and their variations was taken from the NDSR. The current NDSR version includes 160 nutrients and other food components. New nutrients and components are constantly added to meet the emerging research needs.

The consensus is that the FFQ has some limitations since the participants need to recall the amount and frequency of the foods consumed in the last twelve months. Therefore, this method depends on the participant's memory over a relatively long period.

Additionally, it is possible that recent or current dietary habits are cited in place of those practiced during the study period (last twelve months $)^{19}$. Another limitation is related to the accuracy of the amount consumed, since in the FFQ the participant must report intake based on a preestablished cooking unit. The use of an equivalence list may reduce this problem by allowing the participant to report an alternative cooking unit during the interview. The loss of food intake details is also reported in studies that use the $\mathrm{FFQ}^{3,19}$.

One way to minimize some of the problems associated with the FFQ is method calibration, which is possible by using food records from validation studies with 300 participants in the six IC (in press).

\section{Perspectives of diet analysis in ELSA-Brasil}

The analysis of dietary data leads to the quantification of energy, nutrients, foods and food groups, in the classification of individuals according to food intake and in the identification of dietary patterns. These allow testing hypotheses between dietary associations and different outcomes or diseases. Important components for understanding the relationship between diet and 
CVD, diabetes and obesity, such as different dietary fatty acid profiles or dietary glycemic index, only to mention a few, may also be explored and better apprehended in this analysis.

It is possible to identify many diet analysis possibilities and important contributions to the knowledge about the relationship between diet and the chronic diseases present in the Brazilian population. In addition to investigating this issue in a population rather different from those of other longitudinal studies, ELSA-Brasil will test hypotheses generated in Brazilian cross-sectional studies that contemplate diet as a factor of exposure to certain diseases, such as the influence of combining rice and beans on obesity 20,21 .

Although significant accumulated knowledge on the theme already exists, nearly all cohort studies that analyzed these relationships were done in the Northern Hemisphere, including the United States and European countries. Hence, there is a great scarcity of information on the association between diet and CVD in countries similar to Brazil in ethnic diversity combined with recent nutrition transition, common in emerging countries $^{22}$. Both the prevalence and the consequences of these diseases in Brazil are different from those of developed countries. Therefore, one of the main contributions of this analysis will be to identify specific characteristics of the Brazilian diet and their relationship with other specific factors of the Brazilian population and with the outcomes studied in ELSA-Brasil.

One of the study strengths is the possibility of assessing diet using a FFQ sensitive to regional variations. Another ELSA-Brasil advantage is the collection of repeated measures with regular periodicity, constituting an extremely important condition for the long-term dietary assessment and the relationship between diet and chronic diseases. An important contribution of this study will be the identification and exploration of regional differences and their impact on certain equally regional outcomes, regardless of other lifestyle factors.
Another important contribution of ELSA-Brasil is the possibility of measuring the urinary excretion of sodium in 12 hours, allowing the study of the correlation between sodium excretion and diet. Together, these tools will provide a very thorough dietary analysis and improve the knowledge about the relationship between diet and CVD and diabetes in Brazil. Brazilians inherited from the Portuguese the habit of consuming too much salt ${ }^{23}$, making hypertension an important risk factor for cardiovascular diseases and consequently, for fatal strokes ${ }^{24,25}$.

Other possible analyses include the use of scores that compare ELSA participants' diets with other diets known to protect against CVD, such as the Mediterranean and DASH diets. Trichopoulous et al assessed adherence to the Mediterranean diet in adult Greeks using a scale from 0 to $9(9=$ total adherence and $0=$ no adherence) and found that greater adherence was associated with lower mortality from ischemic heart disease and cancer ${ }^{25}$. Fung et al. ${ }^{26}$ observed an inverse association between the DASH score based on eight food/nutrient groups (fruits, vegetables, whole grains, nuts, low-fat dairy products, red and processed meats, sweetened beverages and sodium) and stroke ${ }^{26}$. This type of association is perfectly reproducible in ELSA.

ELSA-Brasil includes a broad battery of tests for cognitive assessment (memory, semantic and phonemic fluency and executive functions). A recent study showed that adherence to a Mediterranean-like diet was associated with smaller age-related cognitive decline ${ }^{27}$. Another study showed that a high intake of n-3 fatty acids reduced verbal fluency decline in individuals with high blood pressure and diabetics ${ }^{7}$. Féart et al. ${ }^{27}$ showed that good adherence to the Mediterranean diet was associated with a smaller cognitive decline according to the mini-mental state examination. Bearing these results in mind, it will be possible not only to assess the association between diet and cognitive decline using ELSA data, but also to compare the results with other similar studies. 
ELSA-Brasil also allows assessing FFQ performance in populations other than those that participated in validity studies in developed countries. If a validity study is done, it will be possible to use it in other investigations in the Brazilian population. This validity study was designed to determine if the newly created FFQ classifies individuals into different intake levels well. Three hundred participants were studied in the six IC (50 in each center) using the food record method as reference. Each participant recorded all foods and beverages consumed within 24 hours on three different occasions (October, March and August), with regular intervals during twelve months. Since the ELSA sample includes three occupational categories (support, technical and higher education levels), it is possible to analyze the FFQ performance according to these categories, as well as in relation to education level, age group and gender.

The risk factors for CVD have different distributions in different countries and diet is one of the factors that most contributes to this difference, as shown by the Seven Countries Study ${ }^{28,29}$. In addition to allowing comparisons among the six centers, ELSA allows comparing how diet is a risk factor for CVD in Brazil and developed countries. This piece of the puzzle that ELSA begins to unveil can be added to the existing knowledge to construct a more complete picture of the distribution of CVD and diabetes and their global risk factors. As mentioned by Willett et al. ${ }^{15}$, developing countries usually have unique dietary characteristics and variations, and possibly different genetic susceptibilities to the effect of diet that justify the performance of well-designed cohort studies in these populations.

\section{ACKNOWLEDGMENTS}

The present study was possible thanks to the technical and financial support provided by the Ministry of Health, Department of Science, Technology and Strategic Inputs, Department of Science and
Technology, Ministry of Science and Technology, National Council for the Development of Science and Technology, Sponsor of Studies and Projects to the Longitudinal Study of Adult Health ELSA-Brasil.

\section{CONTRIBUTORS}

MCB MOLINA, CP FARIA, LO CARDOSO, M DREHMER, G VELASQUEZ-MELÉNDEZ, C MELERE, ALC GOMES, and I BENSENOR contributed to the study design, data collection, writing and review of the manuscript. MFHS DINIZ and R SICHIERI contributed to the review the article.

\section{REFEREN CES}

1. Jakobsen MU, O’Reilly EJ, Heitmann BL, Pereira MA, Bälter K, Fraser GE, et al. Major types of dietary fat and risk of coronary heart disease: A pooled analysis of 11 cohort studies. Am J Clin Nutr . 2009; 89(5):1425-32. doi: 10.3945/ajcn.2008.27124.

2. Carter P, Gray LJ, Troughton J, Khunti K, Davies MJ. Fruit and vegetable intake and incidence of type 2 diabetes Mellitus: Systematic review and meta-analysis. BMJ. 2010; 341(18):c4229. doi: 10.1136/bmj.c4229.

3. Willett WC, Reynolds RD, Cottrell-Hoehner S, Sampson L, Browne ML. Validation of a semiquantitative food frequency questionnaire: Comparison with a 1-year diet record. J Am Diet Assoc. 1987; 87(1):43-7.

4. Block G, Hartman AM, Dresser CM, Carroll MD, Gannon J, Gardner L. A data-based approach to diet questionnaire design and testing. Am J Epidemiol. 1986; 124(3):453-69.

5. Nurses Health Study. Boston (MA) [cited 2012 Sept 20]. Available from: <http://www.channing. harvard.edu/nhs/>.

6. Fung TT, Rexrode KM, Mantzoros CS, Manson JE, Willett WC, Hu FB. Mediterranean diet and incidence of and mortality from coronary heart disease and stroke in women. Circulation. 2009; 119(8):1093-00. doi: 10.1161/CIRCULATIONAHA. 108.816736.

7. Devore EE, Stampfer MJ, Breteler MM, Rosner B, Kang J H, Okereke O, et al. Dietary fat intake and cognitive decline in women with type 2 diabetes. Diabetes Care. 2009; 32(4):635-40. doi: 10.2337/d c08-1741.

8. Forman JP, Stampfer MJ, Curhan GC. Diet and lifestyle risk factors associated with incident 
hypertension in women. JAMA. 2009; 302(4):401-11. doi: 10.1001/jama.2009.1060.

9. Kaushik M, Mozaffarian D, Spiegelman D, Manson JE, Willett WC, Hu FB. Long-chain omega-3 fatty acids, fish intake, and the risk of type 2 diabetes Mellitus. Am J Clin Nutr. 2009; 90(3):613-20. doi: 10.3945/ajcn.2008.27424

10. Joshipura KJ, Hung HC, Li TY, Hu FB, Rimm EB, Stampfer MJ, et al. Intake of fruits, vegetables and carbohydrate and the risk of CVD. Public Health Nutr. 2009; 12(1):115-21. doi: 10.1017/S1368980 008002036.

11. Framingham Heart Study. [cited 2012 Sept 20]. Available from: <http://www.framingham heartstudy.org>.

12. Whitehall Studyn London: UCL [cited 2012 Sept 20]. Available from: <http://www.ucl.ac.uk/ whitehall|l>.

13. McNaughton SA, Mishra GD, Brunner EJ. Dietary patterns, insulin resistance and incidence of type 2 diabetes in the Whitehall II study. Diabetes Care. 2008; 31(7):1343-48. doi: 10.2337/dc07-1946.

14. Aquino EML, Barreto SM, Bensenor IM, Carvalho MS, Chor D, Duncan BB, et al. Brazilian Longitudinal Study of Adult Health (ELSA-Brasil): Objectives and design. Am J Epidemiol. 2012; 15;175(4):315-24. doi: 10.1093/aje/kwr294

15. Willett WC. Future research directions. In: Willet WC, editor. Nutritional epidemiology. $2^{\text {th }}$ ed. New York: Oxford University Press; 1998.

16. Sichieri R. Estudo de validação do questionário de frequência de consumo de alimentos. In: Sichieri $\mathrm{R}$, editor. Epidemiologia da obesidade. Rio de Janeiro: EdUERJ; 1998.

17. Sichieri R, Everhart JE. Validity of a brazilian food frequency questionnaire against dietary recalls and estimated energy intake. Nutr Res. 1998; 18(10): 1649-59. doi: 10.1016/S0271-5317(98)00 151-1.

18. Pinheiro ABV, Lacerda EMA, Benzecry EH, Gomes MCS, Costa VM. Tabela de composição de alimentos. São Paulo: Atheneu; 2004.

19. Fisberg RM, Martini LA, Slater B. Métodos de inquéritos alimentares. In: Fisberg RM, Slater B, Marchioni DML, Martini LA, organizadores. Inquéritos alimentares: mé-todos e bases científicos. São Paulo: Manole; 2005.
20. Sichieri R. Dietary patterns and their associations with obesity in the Brazilian city of Rio de Janeiro. Obes Res. 2002; 10(1):42-8. doi: 10.1038/oby.20 02.6 .

21. Sichieri R, Moura AS, Genelhu V, Hu F, Willett WC. An 18-mo randomized trial of a low-glycemic-index diet and weight change in Brazilian women. Am J Clin Nutr. 2007; 86(3):707-13.

22. Coutinho JG, Gentil PC, Toral N. Malnutrition and obesity in Brazil: Dealing with the problem through a unified nutritional agenda. Cad Saúde Pública. 2008; 24(Suppl 2):S332-40. doi: 10.1590/S0102-3 $11 \times 2008001400018$.

23. Mackenbach JP. Bacalhao under the Ponte 25 de April: Impressions form Lisbon. Eur J Public Health. 2009; 19(1):1. doi: 10.1093/eurpub/ckn138.

24. Sarti C, Rastenyte D, Cepaitis Z, Tuomilehto J. International trends in mortality from stroke. Stroke. 2000; 31(7):1588-01. doi: 10.1161/01.STR.31.7.1 588.

25. Trichopoulous A, Costacou T, Bamia C, Trichopoulos $D$. Adherence to a mediterranean diet and survival in a Greek population. N Eng J Med. 2003; 348(26): 2599-608. doi: 10.1056/NEJMoa025039.

26. Fung TT, Chiuve SE, McCullough ML, Rexrode KM, Logroscino G, Hu FB. Adherence to a DASH-Style diet and risk of coronary heart disease and stroke in women. Arch Intern Med. 2008; 168(7):713-20. doi: 10.1001/archinte.168.7.713.

27. Féart C, Samieri C, Rondeau V, Amiera H, Portet F, Dartigues JF, et al. Adherence to a Mediterranean diet, cognitive decline and risk of dementia. JAMA 2009; 302(6):638-48. doi: 10.1001/jama.2009.1 146

28. Ancel K, Mienotti A, Karvonen MJ, Aravanis C, Blackburn H, Buzina R, et al. The diet and 15-year death rate in the Seven Countries Study. Am J Epidemiol 1986; 124(6):903-15.

29. Menotti A, Kromhout D, Blackburn H, Fidanza F, Buzina R, Nissinen A. Food intake patterns and 25-year mortality from coronary heart disease: Cross-cultural correlations in the Seven Countries Study. The Seven Countries Study Group. Eur J Epidemiol 1999; 15(6):507-15.

Received on: 18/7/2012

Final version on: 4/10/2012 Approved on: 13/11/2012 